\title{
Long-term effectiveness of oral vanadyl sulphate in streptozotocin-diabetic rats
}

\author{
M.C.Cam ${ }^{1}$, R. A.Pederson ${ }^{2}$, R. W.Brownsey ${ }^{3}$ and J.H.McNeill ${ }^{1}$ \\ ${ }^{1}$ Division of Pharmacology and Toxicology, Faculty of Pharmaceutical Sciences, University of British Columbia, Vancouver, Canada \\ ${ }^{2}$ MRC Regulatory Peptide Group, Department of Physiology, University of British Columbia, Vancouver, Canada \\ ${ }^{3}$ Department of Biochemistry, Faculty of Medicine, University of British Columbia, Vancouver, British Columbia, Canada
}

\begin{abstract}
Summary. Recent studies have demonstrated the insulin-like effects of oral vanadyl sulphate in the streptozotocin-diabetic rat, including the amelioration of hyperglycaemia and the prevention of diabetes-related cardiac and adipose tissue dysfunction. However, the possibility that vanadyl treatment, routinely initiated at 3 days after the induction of diabetes, had prevented the full cytotoxic destruction of the beta cell, and thus accounted for the apparent anti-diabetic properties of vanadyl was questioned. Hence in the present study, we examined the effectiveness of vanadyl sulphate as a glucoselowering and anti-diabetic agent when administration was delayed from the time of induction of diabetes. Male Wistar rats were injected with a single intravenous dose of streptozotocin $(55 \mathrm{mg} / \mathrm{kg})$. Vanadyl sulphate was administered in the drinking water at a concentration of $0.75 \mathrm{mg} / \mathrm{ml}$ from 3,10 and 17 days after the streptozotocin injection and treatment was then maintained for 5 months. Vanadyl intake was accompanied by lowered serum levels of triglyceride and cholesterol with no associated enhancement in circulating insulin. Vanadyl-treated diabetic animals showed improved glucose tolerance while insulin release in vivo was still markedly lower than in non-diabetic rats. Adipose tissue func-
\end{abstract}

tion, as expressed by basal and epinephrine-stimulated lipolysis in isolated adipose tissue, was also normalized in vanadyl-treated diabetic animals. These responses were all observed whether vanadyl treatment was initiated 3,10 or 17 days after induction of diabetes. Finally, prolonged treatment with vanadyl sulphate (in this case up to 5 months) did not cause any apparent hepatic toxicity as assessed histologically. Diabetes-induced morphological changes in the kidney were also prevented by vanadyl treatment. Thus, these findings support the concept that the efficacy of vanadyl treatment is unrelated to protection from the acute toxic effects of streptozotocin on pancreatic beta cells. Further, these studies provide additional support for the notion suggested in earlier studies that either improved pancreatic function may result from the alleviation of hyperglycaemia by vanadium treatment or that some residual pancreatic function which in itself is insufficient to prevent the onset and progression of the diabetic state may contribute to an effective response to administered vanadium.

Key words: Diabetes mellitus, vanadyl sulphate, glucose, pancreas, streptozotocin.
The insulin-mimetic actions of vanadium have been well documented both in vitro and in vivo and these include enhancement of glucose transport and oxidation in rat adipocytes and skeletal muscle [1-3], inhibition of lipolysis [4] and activation of lipogenesis in rat adipocytes [5], prevention of cardiac [6] and lipid [7] abnormalities in the streptozotocin (STZ)-diabetic rat and reduction of insulin requirement in the spontaneously diabetic (BB Wistar) rat [8]. The ability of vanadium to stimulate the insulin receptor kinase [9-11] as well as to prolong receptor activation [12] and also to exert post-receptor effects $[13,14]$ have all been proposed as possible mechanisms of action.

More recently, euglycaemia was found to be maintained in STZ-diabetic rats which had been withdrawn for 13 weeks from a short period of oral vanadyl treatment
[15]. In these animals, morphological and immunohistochemical analysis revealed that the number of insulinstaining beta cells was increased eight-fold compared to non-treated diabetic rats, though not completely restored to control levels [16]. Further, the insulin-secretory response of the isolated perfused pancreas to glucose, though suppressed compared to non-diabetic control rats, was higher than in non-treated diabetic rats [16]. Since vanadyl treatment in these studies was initiated 3 days after the STZ injection, a time when pancreatic islet cell area and insulin content were not significantly diminished, it is possible that vanadium treatment had allowed some protection of the pancreatic beta cells from STZ-induced cytotoxicity and in so doing, prevented a full expression of the diabetic state. Indeed, further support for this hypo- 
thesis came from recent studies in which it was shown that the intraperitoneal infusion of vanadyl prior to the administration of STZ fully protected pancreatic beta cells against STZ-induced cytotoxicity [17].

These findings thus suggest that the observed insulinmimetic effects of oral vanadyl in our previous studies may in part be due to its actions at the level of the pancreas. Thus, it was considered crucial to determine if the effectiveness of vanadyl treatment depended on its presence at a time when a critical number of remaining viable beta cells could be protected from further destruction by circulating STZ or hyperglycaemia or both. The present studies were designed to address this problem by initiating treatment with vanadyl sulphate at different intervals after the onset of STZ-induced diabetes. We therefore investigated the effects of vanadyl administration on both glucose homeostasis and pancreatic function when treatment was begun 3,10 or 17 days after the induction of diabetes. Furthermore, vanadium treatment was continued for 5 months to provide a further opportunity to observe possible toxicological aspects of oral vanadyl treatment over an extended period.

\section{Materials and methods}

\section{Treatment and maintenance of animals}

Male Wistar rats weighing between 200-250 g and fed ad libitum were used. Diabetes was induced by an i.v. injection of STZ (Sigma Chemical Co., St. Louis, Mo., USA) at a dose of $55 \mathrm{mg} / \mathrm{kg}$ while control rats received only vehicle (154 mmol// NaCl, $\mathrm{pH} 7.2)$. At 3 days following the STZ injection, blood glucose was checked by glucometer and animals exhibiting blood glucose levels greater than $13.75 \mathrm{mmol} / 1$ were considered diabetic. Control rats were divided into treated (CT, $n=12)$ and non-treated $(C, n=12)$ groups, while diabetic rats were divided into four groups which were: non-treated (D, $n=11)$, or treated with administration of vanadyl starting at 3 (DT3, $n=12$ ), 10 (DT10, $n=11$ ) and 17 (DT17, $n=16$ ) days following the STZ injection. All treated animals were given vanadyl sulphate at a concentration of $0.75 \mathrm{mg} / \mathrm{ml}$ in the drinking water (VOSO ${ }_{4} \cdot 3 \mathrm{H}_{2} 0$, Fisher Scientific Co., Fair Lawn, NJ, USA). Vanady]. solutions were replaced twice weekly. The $\mathrm{pH}$ and colour of the solution was checked and found to be unchanged over a 2-week period. The concentration of vanadyl used in this study was based on our previous observations that a desirable combination of improved body weight and glycaemic control resulted when vanadyl sulphate was provided at a concentration of $0.75 \mathrm{mg} / \mathrm{ml}$ in the drinking water [7]. Treatment for CT rats commenced at the same time as DT3. For 15 weeks, plasma glucose, body weight, and food and fluid intake were closely monitored. The daily vanadyl dose was calculated as the mean volume consumed per $\mathrm{kg}$ body weight multiplied by the concentration of the solution. The treatment of animals was terminated at 5 months at which time plasma samples were obtained for the determination of triglyceride (TG) and cholesterol levels (Boehringer Mannheim Canada, Laval, Quebec, Canada), insulin by RIA (Immunocorp, Montreal, Quebec, Canada), glutamic-oxalacetic transaminase (GOT) and blood urea nitrogen (BUN) by kits obtained from Sigma. Oral glucose tolerance tests and pancreatic perfusion studies were carried out and adipose tissues were obtained for further procedures described below.

\section{Oral glucose tolerance test}

At 5 months into the experiment, rats were fasted overnight and an oral glucose dose ( $1 \mathrm{~g} / \mathrm{kg}$ as a $40 \%$ solution) was administered to the conscious animals by gavage. Blood samples were obtained before and at 10,20,30, and 60 min after glucose administration and collected into heparinized capillary tubes from the tail vein. Insulin was measured by RIA using purified rat insulin standard (Novo, Copenhagen, Denmark) and antiserum raised in guinea pig.

\section{Pancreatic perfusion}

Following an oral glucose tolerance test, some rats were anaesthetized with $60 \mathrm{mg} / \mathrm{kg}$ pentobarbital and the pancreas and associated duodenum were isolated ( $n: \mathrm{C}=5, \mathrm{CT}=5, \mathrm{D}=5, \mathrm{DT} 3=6, \mathrm{DT} 10=5$, DT17 $=6$ ). Insulin secretion was measured in isolated pancreata perfused with $16.65 \mathrm{mmol} / 1$ glucose plus a gradient $(0-1 \mathrm{ng} / \mathrm{ml})$ of the insulinotropic hormone gastric inhibitory polypeptide (GIP) as described previously [18]. Perfusate consisted of a modified Krebs-Ringer bicarbonate buffer containing 3\% dextran and $0.2 \%$ bovine serum albumin and gassed with $95 \% \mathrm{O}_{2} / 5 \% \mathrm{CO}_{2}$ to achieve a $\mathrm{pH}$ of 7.4. Portal outflow was collected at 1 -min intervals at a rate of $4 \mathrm{ml} / \mathrm{min}$ after a 10 -min equilibration. Perfusate samples were subsequently analysed for insulin content.

\section{Glycerol output from isolated adipose tissue}

These experiments were conducted on some of the animals ( $n: \mathrm{C}=6$, $\mathrm{CT}=6, \mathrm{D}=5, \mathrm{DT} 3=6, \mathrm{DT} 10=6, \mathrm{DT} 17=5$ ). At the time of killing, epididymal fat pads were removed and immediately incubated at $37^{\circ} \mathrm{C}$ in Krebs-Henseleit bicarbonate buffer containing $2 \mathrm{mg} / \mathrm{ml} \mathrm{glu}$ cose and defatted serum albumin ( $2 \%$ weight/volume). Following 30 min of incubation, fat pads were incubated in the presence or absence of insulin at a final concentration of $1 \mathrm{mU} / \mathrm{ml}$ for $30 \mathrm{~min}$, after which epinephrine was added to the incubation medium for an additional $30 \mathrm{~min}$ at a concentration of $1 \mu \mathrm{g} / \mathrm{ml}$. At the end of the incubation period, pads were removed and weighed. Incubation mixtures were heated at $95^{\circ} \mathrm{C}$ for $10 \mathrm{~min}$ and stored at $-70^{\circ} \mathrm{C}$ for subsequent glycerol analysis, using commercial kits (Boehringer).

\section{Tissue histopathology}

Liver and kidney slices were analysed histologically for any apparent toxicological effects of the 5-month oral vanadyl treatment on the primary organs. Tissues were fixed in $10 \%$ buffered formalin, dehydrated and embedded in paraffin. Sections were stained in haematoxylin and eosin.

\section{Vanadium levels}

At termination, samples of tissue from kidney, liver, muscle and bone were analysed for vanadium levels using a VarianAA-1275 spectrophotometer as described previously [19].

\section{Statistical analysis}

All results are expressed as means \pm SEM. The data were analysed using MANOVA followed by the Newman Keul's or Fisher test. $p<0.05$ indicated statistical significance.

\section{Results} Effects of vanadyl treatment on body weight, food and
fluid intake, and plasma glucose

Overall increase in body weight over a 15 -week period (Fig.1A) was depressed in the STZ-diabetic animals and did not appear to be corrected by vanadyl treatment. 

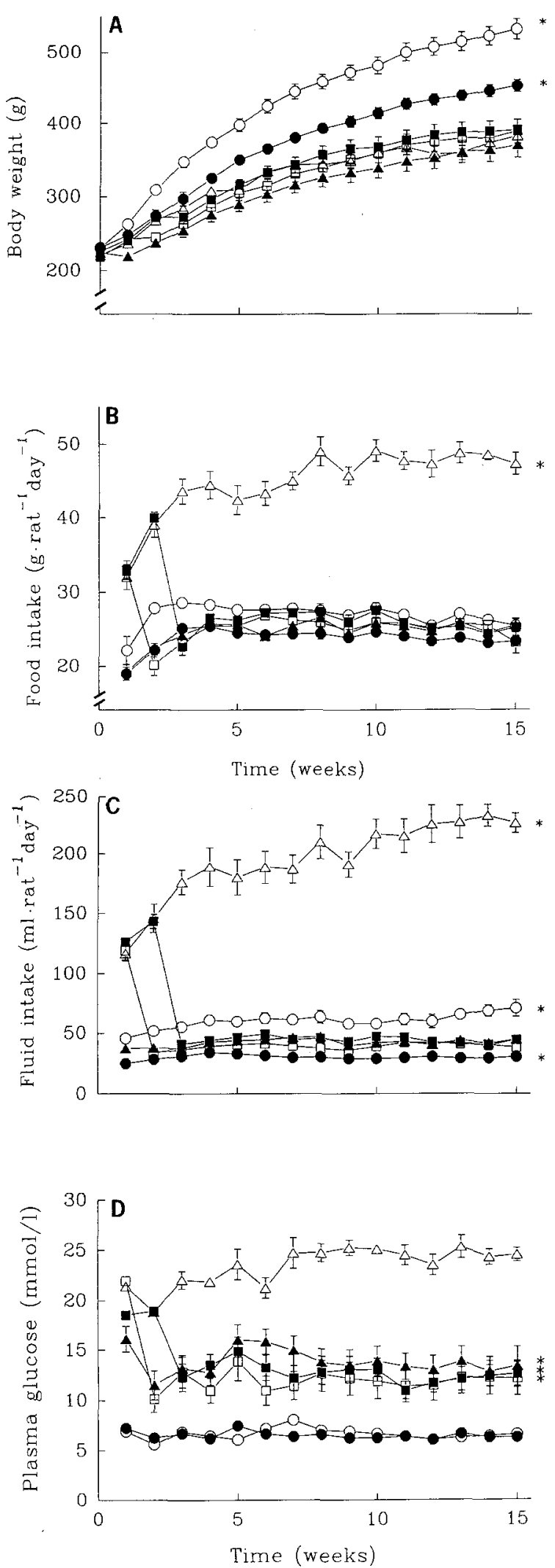

Fig. 1A-D Body weight (A), daily food (B), fluid (C) and plasma glucose $(\mathbf{D})$ of control $(O)$, control-treated $(\bullet)$, diabetic $(\triangle)$, and diabetic rats treated with vanadyl sulphate $(0.75 \mathrm{mg} / \mathrm{ml})$ in the drinking water at $3(\boldsymbol{\Delta}), 10(\square)$, and 17 ( $\boldsymbol{\square})$ days after the streptozotocin injection. Values are means \pm SEM. ${ }^{*} p<0.05$ vs all other groups
Vanadyl intake in non-diabetic rats resulted in reduced weight gain compared with non-treated control rats. During the first week of vanadyl treatment, mean body weight of the diabetic-treated (DT) groups dropped, although recovery was evident by the following week.

The induction of diabetes produced the expected symptoms of hyperphagia as manifested by a two-fold increase in food intake (Fig. 1 B). In all DT groups, a parallel lowering of food intake from diabetic to control levels was observed immediately following the onset of treatment. Thus, food intake $\left(\mathrm{g} \cdot \mathrm{rat}^{-1} \cdot \mathrm{day}^{-1}\right)$ among the DT groups at the end of the first week of treatment was not different $(\mathrm{DT} 3=19.2 \pm 1.1$, DT10 $=20.1 \pm 1.4$, DT17 $=22.7 \pm 1.2)$ and remained significantly lower than $\mathrm{C}(p<0.05)$ until week 6 , after which no difference was seen. Food intake was lowered significantly in CT animals throughout the duration of treatment $(p<0.05)$.

Induction of the diabetic state produced an instanta* neous two-fold higher fluid intake which gradually progressed to a four-fold rise in volume at 15 weeks (Fig. 1C). Administration of vanadyl reduced fluid intake below control levels from the first day in both the DT and CT animals and the reduction was maintained throughout the treatment period. One rat in DT10 died of severe dehydration apparently from refusal to drink the vanadyl solution, while another in the DT17 group developed severe diarrhoea and weight loss and was subsequently removed from the experiment. One non-treated diabetic rat was similarly removed due to a severe catabolic condition resulting from the STZ injection. The daily vanadyl intake calculated over a 15-week period showed an overall decrease which was largely accounted for by an increase in body weight while total fluid intake remained constant. The doses calculated at 15 weeks differed at most by $15 \%$ among the DT groups: in $\mathrm{mg} \cdot \mathrm{kg}^{-1} \cdot \mathrm{day}^{-1}\left[\mu \mathrm{mol} \cdot \mathrm{kg}^{-1}\right.$. day $\left.^{-1}\right]$ (DT3, 90.7 \pm 2.3 [418 \pm 11$] ;$ DT10, 75.4 \pm 3.8 [348 \pm 17$]$; DT17, $87.2 \pm 8.8$ [402 \pm 41$])$, and these values were all significantly higher $(50-80 \%)$ than CT $(50.6 \pm 1.6$ $[233 \pm 7])(p<0.05)$.

Following treatment with STZ, all diabetic animals exhibited hyperglycaemia which ranged between $15-$ $25 \mathrm{mmol} / \mathrm{l}$ when measured at 3 days post-STZ injection. Administration of vanadyl significantly and consistently reduced the average plasma glucose levels after 1 week of treatment in the DT groups (Fig. 1D). By the end of a 15week maintenance period, the mean glycaemic level of all DT groups was higher than that observed in non-diabetic control rats, but was significantly less than $D$ and was not found to be different among treated groups. Close inspection of plasma glucose concentrations of each of the DT animals individually over the 15 weeks revealed a considerable range of response to the glucose-lowering effects of vanadyl. Thus, while some animals exhibited consistently normal plasma glucose levels $(<9.0 \mathrm{mmol} / \mathrm{l})$ as measured at 10.00 hours weekly over the duration of treatment, others had glycaemic levels which were lower than diabetic rats $(16.9 \pm 0.9$ vs $25.3 \pm 1.2 \mathrm{mmol} / \mathrm{l})$ but which were still significantly higher than normal. Correspondingly, treated animals were subdivided into euglycaemic (DT-E) and non-euglycaemic (DT-NE) groups. The number of animals which were considered euglycaemic (DT- 
Table 1. Plasma parameters of various groups at 5 months

\begin{tabular}{llllll}
\hline $\begin{array}{l}\text { Groups } \\
(n)\end{array}$ & $\begin{array}{l}\text { Insulin } \\
(\mathrm{mU} / \mathrm{l})\end{array}$ & $\begin{array}{l}\text { Cholesterol TG } \\
(\mathrm{mmol} / \mathrm{l})\end{array}$ & $\begin{array}{l}\text { BUN } \\
(\mathrm{mmol} / 1)\end{array}$ & $\begin{array}{l}\text { GOT } \\
(\mathrm{mmol} / 1)\end{array}$ & $(\mathrm{U} / 1)$ \\
\hline $\mathrm{C}(12)$ & $55(4)$ & $2.0(0.1)$ & $1.6(0.1)$ & $7.0(0.3)$ & $44(3)$ \\
CT $(12)$ & $44(4)^{\mathrm{a}}$ & $1.7(0.1)$ & $1.4(0.2)$ & $7.5(0.2)$ & $36(2)$ \\
D (11) & $30(4)^{\mathrm{b}}$ & $2.8(0.2)^{\mathrm{a}}$ & $3.3(0.5)^{\mathrm{a}}$ & $8.1(0.2)$ & $74(18)^{\mathrm{a}}$ \\
DT3(12) & $37(4)^{\mathrm{b}}$ & $1.9(0.1)$ & $1.5(0.2)$ & $8.2(0.5)$ & $36(3)$ \\
DT10(11) & $36(4)^{\mathrm{b}}$ & $1.8(0.1)$ & $1.6(0.1)$ & $8.2(0.4)$ & $40(5)$ \\
DT17 (16) & $32(3)^{\mathrm{b}}$ & $1.6(0.1)$ & $1.4(0.1)$ & $8.4(0.4)$ & $32(2)$ \\
\hline
\end{tabular}

a Significantly different from all other groups $(p<0.05)$.

${ }^{b}$ Significantly different from $\mathrm{C}(p<0.05)$.

Data is expressed as mean ( $\pm \mathrm{SEM}$ ).

TG, Triglycerides; BUN, blood urea nitrogen; GOT, glutamicoxalacetic transaminase; $\mathrm{C}$, control group non-treated; CT, control group vanadyl treated; D, non-treated diabetic group; DT3, 10, 17, vandadyl treatment starting at 3,10 or 17 days following streptozotocin injection

E) were 4 of $12(33 \%)$ in the DT3 group, 7 of $11(64 \%)$ in the DT10 group, and 6 of $16(38 \%)$ in the DT17 group. Further analysis revealed a strong negative correlation between body weight and glycaemia $(r=-0.77)$ in the DT groups and in the $\mathrm{D}$ group but no apparent correlation was observed for CT rats. The mean body weight of DT-E rats did not differ significantly from CT at 15 weeks ( $429 \pm 8$ vs $447 \pm 8 \mathrm{~g}$, respectively) and was significantly higher than DT-NE or non-treated diabetic rats $(353 \pm 9$ and $382 \pm$ $10 \mathrm{~g}$, respectively) $(p<0.05)$.

Effects of vanadyl on plasma insulin, cholesterol, $T G$, $B U N$ and GOT at 5 months of treatment

The induction of STZ-diabetes resulted in reduced circulating insulin in the fed state, which was not altered by vanadyl treatment over the 5 months of the study (Table 1 ). Plasma insulin in CT was significantly lower than C $(p<0.05)$ but higher than the diabetic groups. Diabetic rats had elevated TG and cholesterol levels which were corrected by vanadyl treatment, in agreement with previous studies $[7,19]$. In addition, when the DT animals were pooled from DT3, DT10 and DT17 groups and analysed according to level of glycaemia attained (DT-E vs DT-NE), no significant differences were seen. Plasma GOT was significantly increased in the D group and was lowered to control levels with treatment. There were no significant changes in BUN levels between the groups.

Since these and all subsequent parameters tested in this study were not significantly altered by delayed treatment with vanadyl, i.e. not significantly different between the DT3, DT10 and DT17 groups, the results on glucose tolerance, pancreatic and adipose tissue function in the DT3, DT10 and DT17 groups were pooled and analysed according to the glycaemic levels achieved in response to vanadyl treatment (i.e. DT-E vs DT-NE).

\section{Oral glucose tolerance test}

Fasting plasma glucose levels of both DT-E $(n=17)$ and DT-NE $(n=22)$ animals were not significantly different from control and were markedly lower than D (Fig. 2A). Plasma insulin concentrations did not differ significantly between the D and DT groups at basal or following a glucose load while the peak insulin of CT was significantly lowered to a level which was not statistically significant from the D and DT groups (Fig. $2 \mathrm{~B}, p<0.05$ ). Although fasting plasma glucose levels in DT-E animals were similar to DT-NE, a greater improvement in glucose tolerance was apparent in the DT-E group compared to DT-NE $(t=30 \mathrm{~min}, 16.78 \pm 0.91$ vs $21.70 \pm 0.74 \mathrm{mmol} / \mathrm{l})$. However, the in vivo insulin response to glucose was not different between DT-E and DT-NE as judged by circulating insulin.

\section{Response of isolated pancreas to $16.65 \mathrm{mmol} / \mathrm{lglucose}$ $+0-1 \mathrm{ng} / \mathrm{ml}$ GIP}

The effects of treatment on the response of the perfused pancreas to glucose plus a GIP gradient is shown in Figure 3. Release of immunoreactive insulin (IRI) from the diabetic perfused pancreas was so low as to be below the limit of detection, while the response from CT animals was not significantly different from non-treated control rats. Insulin release from the pancreas of treated diabetic rats pooled from three treatment groups $(n=17)$ was markedly reduced compared to control rats (in the range of
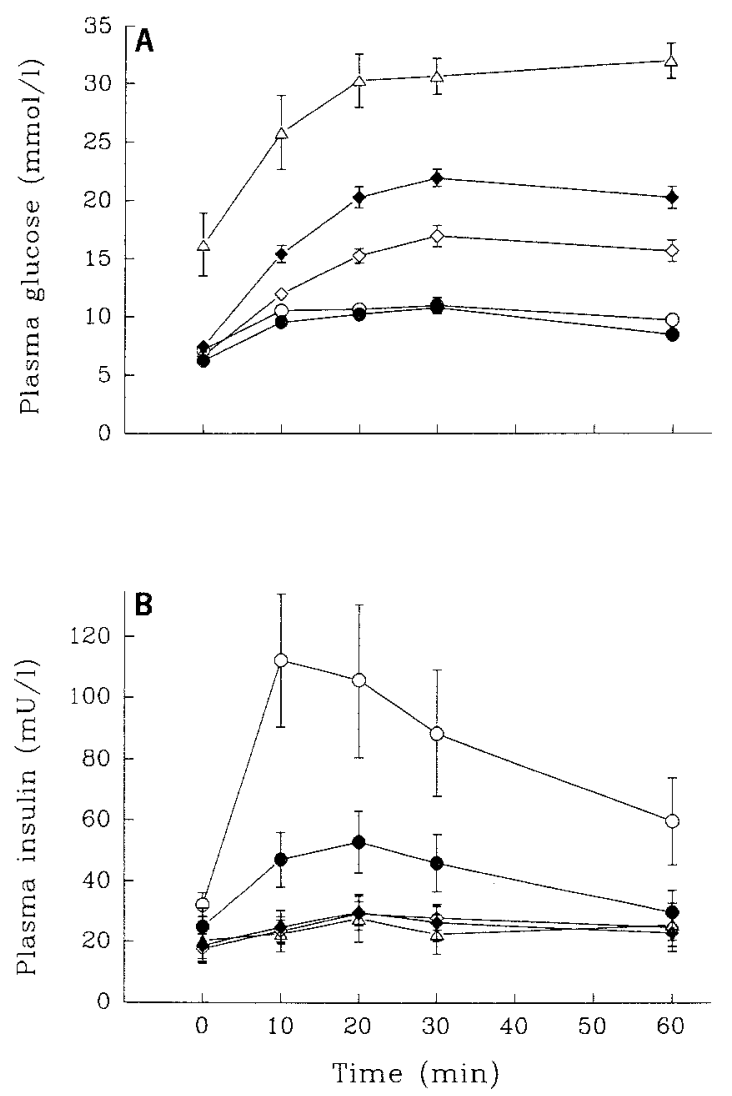

Fig. 2A,B. Plasma glucose $(\mathbf{A})$ and insulin $(\mathbf{B})$ response to an oral glucose challenge $(1 \mathrm{~g} / \mathrm{kg})$ at termination in control $(O)$, controltreated $(\bullet)$, diabetic $(\triangle)$, and diabetic rats treated with vanadyl sulphate $(0.75 \mathrm{mg} / \mathrm{ml})$ in the drinking water at 3,10 and 17 days after the streptozotocin injection, pooled and classified according to glucoselowering response to treatment: euglycaemic (vanadyl sulphate treated diabetic-E, $\Delta$ ) and non-euglycaemic (vanadyl sulphate treated diabetic-NE, $\bullet$ ). See text for details. Values are means \pm SEM 

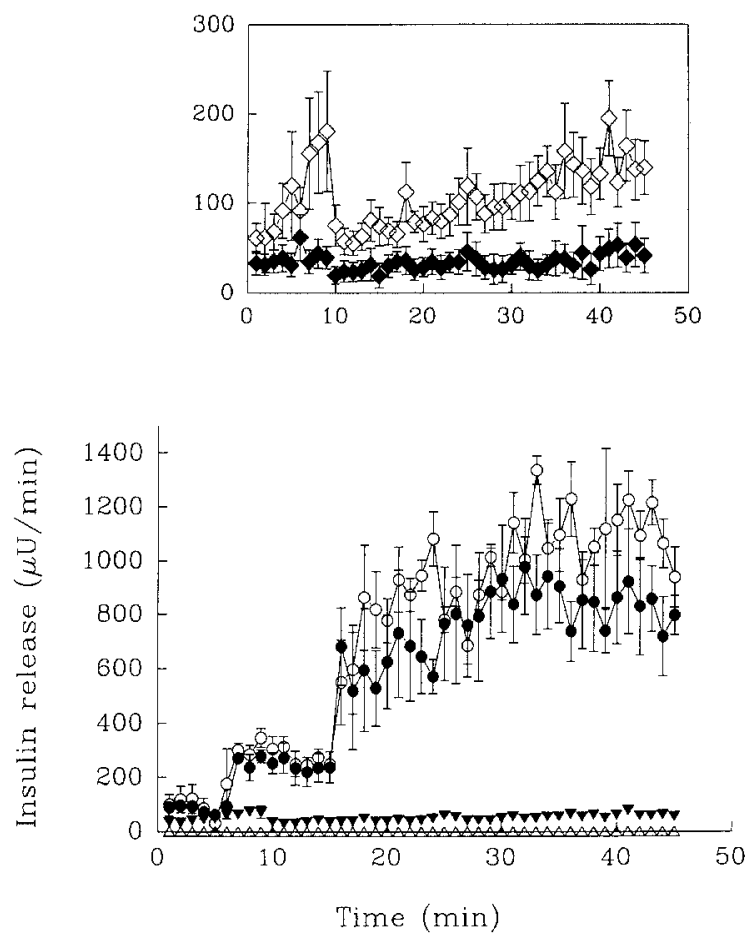

Fig.3. Immunoreactive insulin response to $16.65 \mathrm{mmol} / \mathrm{l}$ glucose with a gradient of $0-1 \mathrm{ng} / \mathrm{ml}$ gastric inhibitory polypeptide from isolated perfused pancreas of control (O), control-treated $(\bullet)$, diabetic $(\triangle)$, and diabetic rats treated with vanadyl sulphate $(0.75 \mathrm{mg} / \mathrm{ml})$ in the drinking water from 3,10 and 17 days after the streptozotocin injection $(\boldsymbol{\nabla})$. Inset shows enhanced $\mathrm{Y}$-axis for diabetic-treated rats pooled and classified according to glucoselowering response to treatment: euglycaemic (vanadyl sulphate treated diabetic-E, $\diamond$ ) and non-euglycaemic (vanadyl sulphate treated diabetic-NE, $\bullet$ ). See text for details. Values are means \pm SEM

$10 \%$ ) but was clearly detectable and significantly elevated compared to release from diabetic rats. Since IRI release was not significantly different between the DT3 $(n=6)$, DT10 $(n=5)$ and DT17 $(n=6)$ groups, the data was analysed according to glycaemic response to treatment. Thus, further expansion of the scale of the figure (inset, Fig. 3) clearly reveals a greater basal insulin release by the DT-E animals $(\mathrm{n}=6)$ as compared to DT-NE $(n=11)$. Insulin release from the DT-NE group was consistently low throughout the period of perfusion. In contrast, release of IRI from the DT-E group showed an early peak which was absent from the DT-NE group and continued to rise slowly and progressively throughout the period of the perfusion.

\section{Glycerol output in isolated adipose tissue}

Figure 4 shows the effects of insulin and/or epinephrine on glycerol output from epididymal fat pads isolated at the time of killing. Basal and epinephrine-stimulated glycerol output was significantly higher in D and DT-NE $(n=10)$ as compared to control rats. In contrast, glycerol released in the basal state was not different between C, CT and DT$\mathrm{E}(n=7)$. Incubation of tissues in the presence of insulin had little effect on low basal rates of glycerol output from $\mathrm{C}, \mathrm{CT}$, or DT-E groups whereas more pronounced inhibi-

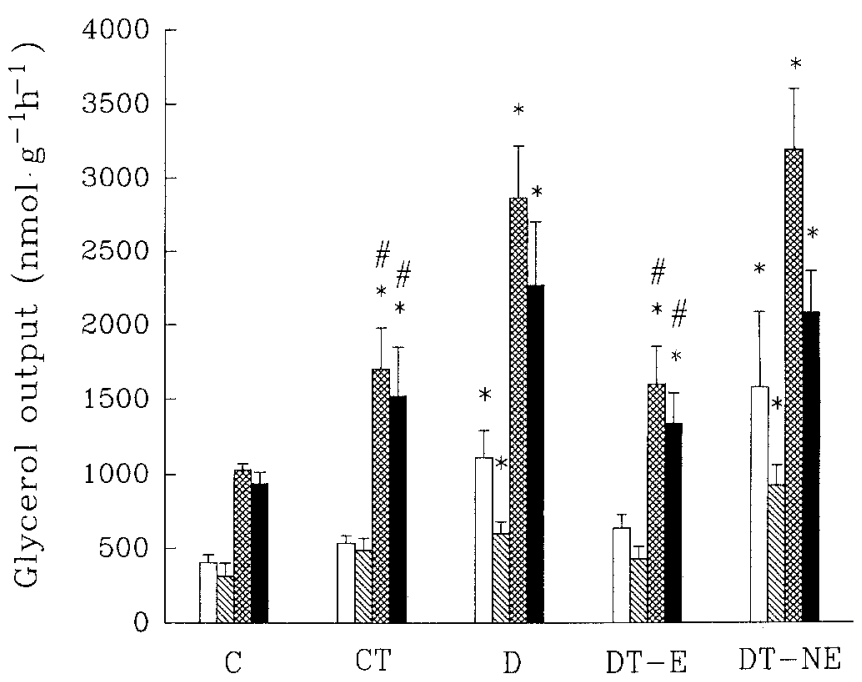

Fig.4. Glycerol output from isolated adipose tissue of control (C), control-treated (CT), diabetic (D), and diabetic rats treated from 3 , 10 and 17 days after the streptozotocin injection, pooled and classified according to glucose-lowering response to treatment: euglycaemic (DT-E) and non-euglycaemic (DT-NE) groups. Adipose

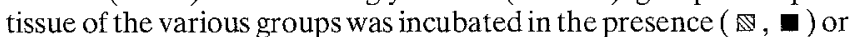
absence ( $\square$, of insulin $(1 \mathrm{mU} / \mathrm{ml})$ followed by epinephrine $(1 \mu \mathrm{g} / \mathrm{ml})(\mathbf{m})$. Values are means $\pm \operatorname{SEM} . * p<0.05$ vs $\mathrm{C}, \#$ $p<0.05$ vs D

tion of lipolysis in D and DT-NE was apparent. In the presence of epinephrine (with or without insulin), glycerol output in the CT and DT-E groups were greater than C although significantly less than D and DT-NE. Fat pad weights were not altered by vanadium treatment in control animals. Pad weights in the DT-E rats were not significantly different from control and were significantly higher than in the D and DT-NE rats $(p<0.05)$.

\section{Histopathology results}

Histological slides of the kidney showed moderately extensive vacuolization and swelling of epithelial cells of the distal convoluted tubules in five out of six non-treated diabetic animals as compared to none in control (data not shown). In contrast, tissue analysis of 5-month vanadyltreated diabetic rats revealed very little to no alterations in kidney structure except for a small renal cell carcinoma in one DT3 animal. The incidence of mild cellular infiltration seen in the medulla of diabetic rats was not altered by vanadyl treatment and was also observed to a similar extent in treated control animals. There were no morphological changes seen in the liver in all groups.

\section{Vanadium levels}

Vanadium levels in tissues analysed in the non-treated control and diabetic groups were less than $0.1 \mu \mathrm{g} / \mathrm{g}$ tissue. In the treated groups, vanadium was found as follows: bone $(4.95 \pm 0.38 \mu \mathrm{g} / \mathrm{g})>$ kidney $(2.42 \pm 0.24 \mu \mathrm{g} / \mathrm{g})$ $>$ liver $(0.95 \pm 0.13 \mu \mathrm{g} / \mathrm{g})>$ muscle $(0.19 \pm 0.03 \mu \mathrm{g} / \mathrm{g})$. There was no correlation between vanadium levels in the tissues studied and the degree to which glucose was 
lowered in response to treatment in the diabetic animals. Also, there were no significant differences in tissue levels of vanadium between DT-E and DT-NE rats. Vanadium levels in muscle and liver agree with the values previously reported when vanadyl sulphate was supplied in the drinking water at a concentration of $0.75 \mathrm{mg} / \mathrm{ml}$ [19], although the levels in bone and kidney are lower, possibly because rats were fasted overnight prior to killing and vanadyl intake was consequently depressed.

\section{Discussion}

The present study demonstrates that the efficacy of oral vanadyl as a glucose-lowering agent is not attenuated by delaying the start of treatment from 3 to 10 or 17 days after the induction of diabetes. Vanadyl treatment led to complete normalization of plasma TG and cholesterol levels and markedly reduced glucose levels to the same extent in all the DT groups. In contrast to the previous study, using rats administered a similar quantity of vanadyl [15], not all animals became completely euglycaemic in the present study. Instead, one subgroup of the treated animals exhibited incomplete reduction of basal glucose levels (DT-NE), while in another subgroup (DT-E), plasma glucose was indeed normal throughout the entire duration of the study. The proportion of animals which became completely normoglycaemic was not lessened in the DT10 and DT17 groups as in the DT3 group. This variability in response may have resulted from varying degrees of STZ-induced beta-cell cytotoxicity or insulin resistance or both in the individual animals since in subsequent studies, we have observed that the number of completely euglycaemic animals is progressively increased by increasing the concentration of vanadyl administered in the drinking water [20]. This progression of DT-NE animals towards the point of true euglycaemia occurred to a similar extent independently of when treatment was initiated. These studies demonstrate that vanadyl is similarly effective in producing a euglycaemic state despite delaying treatment after induction of diabetes and therefore, it is most unlikely that the anti-diabetic efficacy of vanadyl depends on its ability to directly inhibit the cytotoxic effects of STZ.

In view of the disparity in the glucose-lowering response to vanadyl, it was important to determine any correlation between pancreatic function with the degree to which plasma glucose was reduced in the DT animals. Studies have indicated conflicting results in which treatment of STZ-diabetic rats with vanadate, which began between 7-10 days after the STZ injection, led to either no changes in insulin-staining cells [21], or modest increases in pancreatic insulin content, which reached 6-7\% [22] and $34 \%$ [23] of control values. In the present study, the group of animals which exhibited complete euglycaemia under basal conditions (DT-E) showed circulating IRI values and IRI during a glucose tolerance test markedly lower than $\mathrm{C}$ and indistinguishable from $\mathrm{D}$ or DT-NE. In contrast to these observations, the DT-E group did in fact demonstrate markedly enhanced glucose tolerance compared to both DT-NE and D (though still not equivalent to control rats). Furthermore, in perfusion studies, in vitro insulin secretion from pancreata of DT-E animals was significantly higher than in DT-NE or D though, again, substantially lower than in non-diabetic control rats. Of particular note was the gradual increase in the rate of insulin secretion in DT-E throughout the period of pancreas perfusion. It therefore appears that studies of secretion from isolated perfused pancreas reveal some improved function in response to vanadyl treatment which is not apparent from the determination of circulating IRI in vivo but which is nevertheless apparently reflected in improved glucose tolerance. Since these responses to vanadium are achieved after the cytotoxic action of STZ is completed [24], it appears that a subsequent, albeit limited, recovery of pancreatic function occurred in the DT-E group. Although this effect might be attributed to the alleviation of chronic hyperglycaemia $[25,26]$, chronic treatment of neonatal STZ-injected rats with vanadate did not improve beta-cell response to glucose [27], despite the appearance of normoglycaemia. Thus, the presence of the observed residual pancreatic function as a cause or an effect of a full response to vanadium treatment may require additional studies.

The observation that the DT-E group displays basal euglycaemia despite circulating IRI which are very similar to values in DT-NE or D groups suggests enhanced sensitivity of the DT-E group (relative resistance of D and DT-NE) to the residual endogenous insulin or the available vanadium or both which are still present throughout treatment. In agreement with previous reports $[7,15]$, treatment with vanadyl led to normalized adipose tissue lipolytic function, as evidenced by a correction in basal glycerol release rate from adipose tissue isolated from DT-E. However, there was no improvement in basal or catecholamine-induced lipolytic rates in the DT-NE group. These results are consistent with the hypothesis that the conservation of tissue function may be secondary to the amelioration of the hyperglycaemic state. However, the responses of peripheral tissues to vanadium may be more complex. For instance, defects in muscle glycogen synthesis which do not appear to be secondary to glycaemic status have been reported to be improved with vanadate treatment [25].

The studies described represent what we believe to be the longest treatment so far with a vanadium compound. Treatment did not appear to affect the morphology of the liver and prevented some morphological changes in the kidney which were observed in the non-treated diabetic animals. This protective effect of vanadium treatment on the kidney was not secondary to a correction in glycaemic levels since both DT-E and DT-NE animals exhibited a similar lack of pathological lesions. These findings support a previous study [19] in which the occurrence of cellular swelling in the kidney was diminished markedly with a short-term administration of vanadyl sulphate to STZdiabetic rats. However, discrete patches of cellular infiltration in the medulla of treated control animals may suggest the presence of mild inflammation, and whether this phenomenon is a manifestation of a toxic effect of vanadyl and is reversible upon withdrawal from treatment requires further examination. 
In summary, several important points were established in this study. Delaying vanadyl treatment for up to 2 weeks following the induction of STZ-diabetes did not impair the ability of vanadyl to exert its glucose-lowering effects. It seems most likely that the effects of oral vanadyl in the STZ-diabetic rat involve direct effects on the peripheral target tissues at the level of insulin receptor or post-receptor events which are not dependent upon normalized beta-cell function. In addition, vanadium treatment may also lead to some restoration of pancreatic function. The modest improvement of insulin availability may, in combination with vanadium, be responsible for the significant amelioration of the diabetic state. The prevention of most abnormalities in the diabetic kidney during 5 months of treatment provides an additional impetus to explore the mechanism(s) of action of vanadium in the STZ-diabetic rat and in other available models of diabetes.

Acknowledgements. We thank Ms. J. Faun, G. Dong and Ms. M. Battell for their expert technical assistance. Histological slides for kidney and liver were reviewed by Drs. A. Magil and D. Owen, respectively of the Pathology Department at the University Hospital, Vancouver and by Dr. S. Dai of the Faculty of Pharmaceutical Sciences at the University of British Columbia. Vanadium levels were measured by Dr. G. Cros of the Laboratory of Pharmacodynamics, Faculty of Pharmacy, Montpellier, France. This work was supported by the Canadian Diabetes Association (JHM) and by grants from the Medical Research Council of Canada (to RAP, RWB).

\section{References}

1. Dubyak GR, Kleinzeller A (1980) The insulin-mimetic effects of vanadate in isolated rat adipocytes. Dissociation from effects of vanadate as a $\left(\mathrm{Na}^{+}-\mathrm{K}^{+}\right)$-ATPase inhibitor. $\mathbf{J}$ Biol Chem 255: $5306-5312$

2. Schecter Y, Karlish SJD (1980) Insulin-like stimulation of glucose oxidation in rat adipocytes by vanadyl (IV) ions. Nature 284: 556-558

3. Clark AS, Fagan JM, Mitch WE (1985) Selectivity of the insulinlike actions of vanadyl on glucose and protein metabolism in skeletal muscle. Biochem J 232: 273-276

4. Duckworth WC, Solomon SS, Liepnieks J, Hamel FG, Hand S, Peavy DE (1988) Insulin-like effects of vanadate in isolated rat adipocytes. Endocrinology 122: 2285-2289

5. Schecter Y, Ron A (1986) Effect of depletion of phosphate and bicarbonate ions on insulin action in rat adipocytes. $J$ Biol Chem 261: 14945-14950

6. Heyliger CE, Tahiliani AG, McNeill JH (1985) Effect of vanadate on elevated blood glucose and depressed cardiac performance of diabetic rats. Science 227:1474-1477

7. Ramanadham S, Mongold JJ, Brownsey RW, Cros GH, McNeill $\mathrm{JH}$ (1989) Oral vanadyl sulphate in the treatment of diabetes mellitus in the rat. Am J Physiol 257: H904-F911

8. Ramanadham S, Cros GH, Mongold JJ, Serrano JJ, McNeill JH (1990) Enhanced in vivo sensitivity of vanadyl-treated diabetic rats to insulin. Can J Physiol Pharmacol 68: 486-491

9. Tamura S, Brown TA, Dubler RE, Larner J (1984) Insulin-like effect of vanadate on adipocyte glycogen synthase and on phosphorylation of 95,000 dalton subunit of insulin receptor. Biochem Biophys Res Commun 113: 80-86

10. Bernier M. Laird DM, Lane MD (1988) Effect of vanadate on the cellular accumulation of pp15, an apparent product of insulin receptor tyrosine kinase action. J Biol Chem 263: 13525-13534
11. Cordera R, Andraghetti G, DeFronzo RA, Rossetti L (1990) Effect of in vivo vanadate treatment on insulin receptor tyrosine kinase activity in partially pancreatectomized diabetic animals. Endocrinology 126: 2177-2183

12. Fantus EG, Kadota S, Deragon G, Foster B, Posner B (1989) Pervanadate [Peroxide(s) of vanadate] mimics insulin action in rat adipocytes via activation of the insulin receptor tyrosine kinase. Biochemistry 28: 8864-8871

13. Green A (1986) The insulin-like effect of sodium vanadate on adipocyte glucose transport is mediated at a post insulin-receptor level. Biochem J 238: 663-669

14. Strout HV, Vicario PP, Saperstein R, Slater EE (1989) The insulin-mimetic effect of vanadate is not correlated with insulin receptor tyrosine kinase activity nor phosphorylation in mouse diaphragm in vivo. Endocrinology 124: 1918-1924

15. Ramanadham S, Brownsey RE, Cros GH, Mongold JJ, McNeill $\mathrm{JH}$ (1989) Sustained prevention of myocardial and metabolic abnormalities in diabetic rats following withdrawal from oral vanadyl treatment. Metabolism 38: 1022-1028

16. Pederson RA, Ramanadham S, Buchan AMJ, McNeill JH(1989) Long-term effects of vanadyl treatment on streptozotocin-induced diabetes in rats. Diabetes 38: 1390-1395

17. Obih P, Wingard M, Olubadewo J (1992) Effectiveness of alzet minipump administration of vanadyl sulphate in prevention of STZ-induced diabetes. FASEB J 6: A1591 (Abstract)

18. Pederson RA, Buchan MAJ, Zahedi AS, Chan CB, Brown JC (1982) Effect of jejunoileal bypass on the enteroinsular axis. Regulatory Peptides 5: 53-63

19. Mongold JJ, Cros GH, Vian Let al. (1990) Toxicological aspects of vanadyl sulphate treatment of diabetic rats. Pharmacol Toxicol 67: 192-198

20. McNeill JH, Cam MC, Pederson R, Faun J (1991) Vanadyl sulphate has prolonged insulin-like effects in the streptozotocindiabetic rat. FASEB J 5: A1311 (Abstract)

21. Bendayan M, Gringas D (1989) Effect of vanadate administration on blood glucose and insulin levels as well as on the exocrine pancreatic function in streptozotocin-diabetic rats. Diabetologia 32: 561-567

22. Brichard SM, Okitolonda W, Henquin JC (1988) Long term improvement of glucose homeostasis by vanadate treatment in diabetic rats. Endocrinology 123: 2048-2053

23. Blondel O, Bailbe D, Portha B (1989) In vivo insulin resistance in streptozotocin-diabetic rats - evidence for reversal following oral vanadate treatment. Diabetologia 32: 185-910

24. Junod A, Lambert AE, Orci L, Pictet R, Gonet AE, Renold AE (1967) Studies of the diabetogenic action of streptozotocin. Proc Soc Exp Biol Med 126: 201-205

25. Rossetti L, Laughlin MR (1989) Correction of chronic hyperglycemia with vanadate, but not with phlorizin, normalizes in vivo glycogen repletion and in vitro glycogen synthase activity in diabetic skeletal muscle. J Clin Invest 84: 892-899

26. Leahy JL, Weir GC (1991) Beta-cell dysfunction in hyperglycaemic rat models: recovery of glucose-induced insulin secretion with lowering of the ambient glucose level. Diabetologia 34 : 640647

27. Serradas P, Bailbe D, Blondel O, Portha B (1990) Abnormal $B$-cell function in rats with non-insulin-dependent diabetes induced by neonatal streptozotocin: effect of in vivo insulin, phlorizin, or vanadate treatments. Pancreas 6: 54-62

Received: 31 July 1992

and in revised form: 10 November 1992

Dr. J.H. McNeill

Faculty of Pharmaceutical Sciences

University of British Columbia

2146 East Mall

Vancouver, B.C.

Canada V6T 1 Z3 